This PDF is a selection from an out-of-print volume from the National Bureau of Economic Research

Volume Title: The Rate and Direction of Inventive Activity: Economic and Social Factors

Volume Author/Editor: Universities-National Bureau Committee for Economic Research, Committee on Economic Growth of the Social Science Research Council

Volume Publisher: Princeton University Press

Volume ISBN: 0-87014-304-2

Volume URL: http://www.nber.org/books/univ62-1

Publication Date: 1962

Chapter Title: Does the Market Direct the Relative Factor-Saving Effects of Technological Progress?

Chapter Author: William Fellner

Chapter URL: http://www.nber.org/chapters/c2117

Chapter pages in book: (p. 171 - 194) 


\title{
Does the Market Direct the Relative Factor-Saving Effects of Technological Progress?
}

\author{
WILLIAM FELLNER
}

YALE UNIVERSITY

IT Is well known that the forces of competition tend to direct individual firms toward adopting methods of production that are in accordance with relative resource scarcities. This proposition assumes a given level of technological knowledge, that is to say, it assumes production functions in which time does not figure as a variable.

The present paper examines the conditions under which inventive activity, resulting in industrial innovations, i.e. in changes in production functions, also becomes directed toward making this activity accord with relative scarcities in the available factors of production. But this theme will not be taken up immediately. First, I shall make a few introductory observations concerning the directing mechanism on a given level of technological-organizational knowledge, and then some of the imperfections of this mechanism will be discussed. This will clear the ground for an analysis of the problem of directed inventions and innovations.

In Figures 1 and 2 the individual firm is faced with average and marginal productivity functions for labor and for capital, respectively. The "factors" measured along the axes are to be interpreted as the current services of workers and of capital goods.

If $O w \div O r$ expresses the ratio of the wage rate to the market rate of interest with which the firm is faced, the ratio of the labor input to the capital input in the firm will be $O L_{1} / O K_{1}$. The graphs do not in general answer the question of the absolute quantity of the labor input and of the capital input, since to assume one of the two inputs as given when we solve for the other input would beg the question.

In the event of linear homogeneous production functions, the total inputs in each firm are indeterminate unless a limitation is introduced from the outside. For example, if capital is rationed to the firm at the quantity $O K_{1}$, or labor at the quantity $O L_{1}$, then the graph indicates

Nore: I am greatly indebted to Charles J. Hitch and Richard R. Nelson for a discussion of the first draft of this paper; to John H. Power, Arthur M. Okun and James Tobin for valuable suggestions; and to Robert $M$. Solow for an exchange of notes which was exceedingly illuminating to me. I made various revisions under the influence of the comments received from these colleagues. 
FIGURE 1

Labor Input

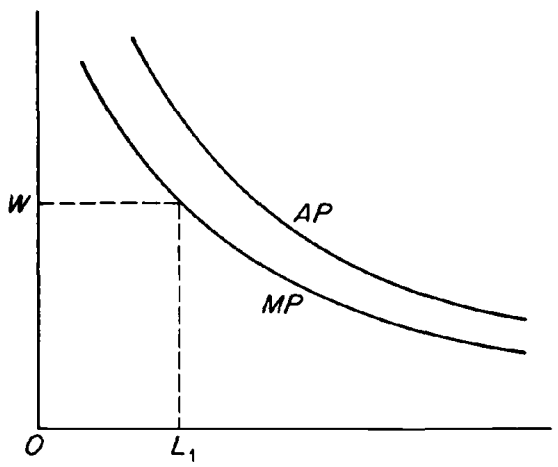

Quantity of capital constant at $O K_{1}$.

FIGURE 2

Capital Input

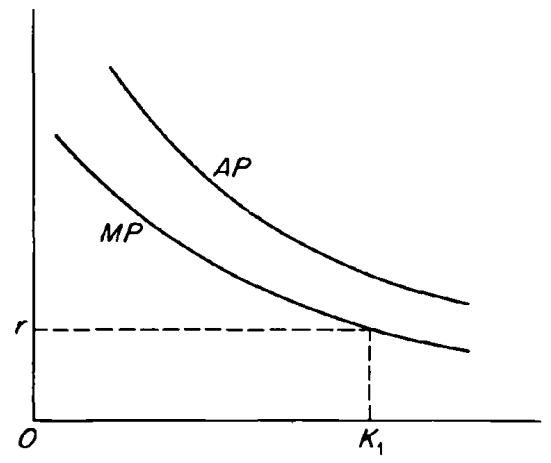

Quantity of labor constant at $O L_{1}$.

correctly the quantity of the nonrationed input. But even in these constant-cost situations where, aside from an outside limitational factor, the absolute size of the inputs is indeterminate, the graph will correctly indicate the input-ratio in the firm which corresponds to any given resource-price ratio (unless even with this input-ratio unit costs exceed the product price, in which case the firm would, of course, be out of business).

The directing mechanism in a competitive cconomy functions through the effect of a macro-economic excess supply of a factor of 
production, or of a macro-economic excess demand for a factor of production, on the relative factor prices with which the individual firms are faced. These factor-price ratios shift in such a way as to induce the firms to use input ratios consistent with the ratios of macroeconomically available supplies. Furthermore, the product-mix also changes in the equilibrating direction. In the event that the production functions are not linear homogeneous but of the kind to which U-shaped average cost curves correspond, not only the input ratios but even the absolute quantities of input in the individual firms become determinate and this conclusion does not require introducing limitational circumstances from the outside. This is because the upward sloping range of the average cost curves always expresses the same sort of deviation from linear homogeneity as the presence behind the scenes of a hidden factor of production which is scarce and rationed to the firm. This hidden factor eliminates the indeterminateness of the absolute size of the labor and of the capital input. In the event of the linear homogeneity the indeterminateness is a consequence of the fact that if both the input of labor and that of capital are increased in the same proportion the higher inputs have the same marginal productivity as the smaller inputs had earlier.

As to the imperfections of the mechanism, in a sense, monopoly power and monopsony power may always be said to misdirect resources. However, not all deviations from perfect competition lead to an aggregative excess supply of factors of production, if by excess supply we mean resources which are idle when their owners would prefer to have them used at going prices. The deviations from perfect competition which can lead to this particular result may be listed in the following way.

1. The directing mechanism described earlier operates with lags. Indeed, even to show conclusively that factor markets will be cleared with a lag would necessitate spelling out dynamic sequences which incorporate assumptions concerning the precise effects of the excess demands and the excess supplies of a period on the price movements from period to period. This is in essence the stability problem. Even if one assigns high probabilities to the presumption that the directing mechanism comes through, i.e. that it is not obviated by events happening on the road toward market clearance, one should recognize that the mechanism does not complete its workings instantaneously. Lags may create underutilization.

2. Lasting rigidities of the money-wage and price level are quite 
likely to put Say's Law out of commission. It is necessary to eliminate Say's Law from our analytical apparatus if imperfections of competition are recognized as causing downward rigidities in the money-wage and price level, because Say's Law can be based only on the realbalance effect, and this in turn presupposes perfect flexibility of the general price level. In a non-Sayian world, unemployment of labor at the existing level of money wages is a possibility even in the long run.

All that is required for such underutilization is that at the given price level the demand for goods out of a full-employment income should fall short of the full-employment supply of goods. If this situation arises the wage-price structure will fail to direct the entire labor force into one or another occupation, and this deficiency of the market process will be a consequence neither of a higher-than-equilibrium real wage level nor of a deficient relative price structure or wage structure. The deficiency will be a consequence of the fact that rates of return on investment have become too low to induce an amount of investment which would match the amount of savings at full employment. If now the general price level does not decline to the point where a plentiful supply of real balances would saturate the demand for liquidity, then the demand for goods does not rise to the level needed for full employment. This is a "Keynesian situation" stated in terms which take account of post-Keynesian contributions. A lowering of the money rate of interest could help, but if the money rate has already declined to a near-zero floor level, the system will necessarily tend to an underemployment level.

In such a Keynesian situation there is an excess supply of labor, even in the long run. An excess supply of capital does not persist in the long run because, while capital may be in excess when a Keynesian situation first develops, nonreplacement will gradually eliminate the excess capacity. Nevertheless, even in the long run the potential full-employment supply of savings and of capital does stay in excess relative to the full-employment demand for capital.

3. There may be underutilization of labor but not of capital also because real wage rates are rigid downward at a level exceeding the marginal productivity of the full labor force with the given capital stock. In situations of this sort an equiproportionate reduction of money wage rates and of prices would not help. An equiproportionate reduction would indeed raise the money demand for goods. But in the case we are now considering unemployment is not a consequence of any insufficiency of demand for an increased output. With a more 
liberal credit policy (lower interest rates) the demand for goods would at any event be sufficient for taking up a bigger output. In the case at hand the potential full-employment supply of savings and of capital would be no greater than the full-employment demand for capital (at interest rates above the floor level). Such a potential excess supply at full employment is not the reason why full employment is out of reach.

If full employment is nevertheless not achieved (and if this is not simply a consequence of the lags in the adjustment process discussed under 1 above), then the reason must be that the actual supply of capital is insufficient to make the ruling real wage rate a full-employment equilibrium wage rate. Hence, the net capital formation which takes place under these conditions of underemployment wherever the propensity to save is positive, will automatically lead to full employment unless the actual real wage rate is gradually further raised or unless other forces tend to reduce that level of the real wage rate which is consistent with full-employment equilibrium. Such other forces may develop from rapid population growth, from the presence of a scarce hidden factor of production, and, as we shall see, from innovations whose relative labor-saving character is very pronounced. If no forces come into play which would reduce the real wage rate consistent with full employment, then gradual capital formation will automatically create full use, at any given real wage rate.

It is this last sentence which is not valid in the event that the underutilization is of the Keynesian variety discussed under 2 above. That sentence draws the line between the two types of general unemployment. In the Keynesian case capital is too abundant relative to labor in an economy in which the levels of money wage rates and of prices are subject to a floor; in the other case labor is too abundant relative to capital in an economy in which the level of real wage rates is subject to a floor. A simpler but still adequate expression of this result is as follows: in the Keynesian case the rate of return on investment would have to be below a floor level in full employment, in the other case the real wage rate would have to be below a floor level in full employment.

\section{A Mechanism Directing the Relative Factor-Saving Effects of Inventions}

We now turn to the main theme of this paper which relates to the role of inventions in creating or preventing the two types of maladjustment described in the concluding paragraph of the preceding section. Any 
market mechanism which one would be willing to regard as directing inventive activity into the correct channels would have to have the property of guiding innovations (and thus the underlying inventions) in a labor-saving direction if an abundance of capital relative to labor is creating one of the two types of maladjustment, and of guiding innovations in a capital-saving direction if a relative abundance of labor is creating the other type of maladjustment.

At this point it is necessary to draw a distinction between the quantity of innovating activity and its character (i.e. its relatively labor-saving or relatively capital-saving character). Given all resource inputs, the output and hence also the average productivity of each factor input will be increased much or little depending upon the quantity of innovating activity. For given resource inputs, the average productivity of each resource (say, of labor and capital) is increased, of course, in precisely the identical proportion, namely, in the proportion in which total output increases. This is true regardless of how relatively labor-saving or capital-saving the innovation may be (regardless, say, of whether we are concerned with labor-saving automation devices or with a capital-saving move from cables to wireless telegraphy). The answer to the question by how much the average productivity of all resources increases depends for given inputs on the quantity of innovating activity, not on its character.

On the other hand, the answer to the question of how innovations influence trends in real wage rates relative to trends in rates of return on investment depends on the relative labor-saving or capital-saving character of innovations. This statement implies of course a macroeconomic way of looking at the matter. To an individual firm possessing no monopsony power, factor prices are given. A relatively laborsaving innovation induces such a firm to use more capital per unit of labor, and a relatively capital-saving innovation induces it to use more labor per unit of capital. But if innovations are adopted on a macroeconomic scale, then the factor-price ratios (and the relative factor shares) change for any given total input of the factors of production.

We shall use the following definition : innovation $A$ is more relatively labor saving, and hence less relatively capital saving, than innovation $\mathrm{B}$ if, for macro-economically given resource inputs, innovation A reduces the relative share of labor more (or raises the relative share of labor less) than does innovation B. ${ }^{1}$ However, the observable trends in distributive shares do not, of course, result exclusively from innova-

\footnotetext{
${ }^{1}$ This definition could, of course, be extended to a three-factor model.
} 
tions. They result jointly from innovations, from movements along production functions, and from changes in the product-mix.

Both the quantity and the character of innovations were here defined for given resource inputs. For the present purpose it is convenient to use given inputs to mean the inputs actually undertaken.

If we further develop our definition of the character of innovations in terms of the marginal productivity theory of distribution (Figures 1 and 2), then it is an essential corollary that we regard an innovation as the less relatively labor saving (the more relatively capital saving), the more it shifts up the marginal productivity function of labor relative to that of capital. Since for given resource inputs the two average productivity functions are shifted up in the same proportion, the relative factor-saving effects are effects on the percentage gaps between average and marginal productivities. This is in accordance with the definition of "labor-saving" and "capital-saving" which was suggested by Hicks in his Theory of Wages.

\section{A NEGATIVE PROPOSITION}

Coming now to the problem of market incentives for the correct slanting of the relative factor-saving effects, we shall first formulate a negative proposition, and subsequently replace it by a positive one which rests on somewhat more complex but, we feel, also on more realistic assumptions.

The negative proposition is that in the event of purely competitive factor hiring, with no factor rationing to individual firms, the market provides no incentive to seek for any given factor inputs one rather than another distribution of the factor-saving effects. This proposition assumes that the individual firm knows for what factor inputs it would be using each available new technology, and that the firm has no objective other than to maximize its profits. We also assume that the cost of acquiring an invention which raises total output in a specific proportion for certain inputs does not depend on whether the marginal productivity of labor is increased in a higher proportion than that of capital or vice versa. In other words, we are concerned here with the question of economic bias, not with that of laboratory bias.

Assume that the firm has the conventional U-shaped cost curves which it can try to lower by seeking new technological knowledge either of a more relatively labor-saving kind or of a more relatively capital-saving kind. The firm expects to earn extra profits, at least temporarily, since the individual firm's ability to innovate does not 
alter prices, wage rates or rentals (say, the relatively high wage rates and low rentals of advanced economies). While the excess profit situation lasts, the following statements are valid, and they make up our negative proposition. One, if with no innovation the firm would have found it most profitable to produce a given output by using, say, 5 units of "cheap" capital for each unit of "expensive" labor, then raising the physical productivity of this specific combination by 10 per cent gives more extra profits than would a 10 per cent productivity increase for any other combination. ${ }^{2}$ Two, if it so happens that with the same difficulty a greater product raising effect can be obtained for a combination other than $5: 1$, then the other combination may, of course, become superior, but there is no reason to assume that the firm would have a predilection for making some other combination superior to the combination $5: 1$. Therefore, the negative part of our conclusion stands. If there exists no laboratory bias, then there exists no systematic bias whatever (in other words, there is no reason to expect systematic economic bias). Even without innovations, increasing macro-economic labor scarcity leads, of course, to a movement toward points of higher capital intensity. But given these points, there is no further inducement to seek innovations of a more relatively labor saving character. ${ }^{3}$

\footnotetext{
${ }^{2}$ This proposition is strictly valid (valid in each individual case) only if the optimum factor ratio does not depend on the scale of operations. If the optimum ratio does change along the firm's cost curves, then the post-innovation output will be produced with a factor ratio which is usually not identical with the ratio with which the same output would have been produced earlier, nor with the ratio with which the actual pre-innovation output was produced. But this introduces merely a random deviation from the negative proposition of the text, since the optimum factor ratio may change either way along various stretches of the cost curves. The reasoning in the present footnote does not point to a systematic economic bias for the innovating process in general.
}

${ }^{3}$ Take for illustration the average capital-productivity function $\left(A P_{k}\right)$ of a firm for a given labor input, and denote several points on the abscissa which are close to each other, as points $K_{1}, K_{2}, K_{3}$, etc. These points on the capital axis stand for increasing inputs of capital, and thus for rising capital intensity. Assume that the firm now operates in $K_{1}$, and that it anticipates a movement toward $K_{2}, K_{3}$, etc. This is the equivalent of the assumption that the firm expects a rise in real wage rates relative to rates of return on investment.

In these circumstances the firm does indeed have an interest in finding through innovation a higher $A P_{k}$ curve which in the next period lies above the present curve mainly in the region around $K_{2}$; and subsequently the firm will have an interest in producing a further upward shift mainly in the region around $K_{3}$. But there exists no presumption that within these regions the firm would want to shift up the curve at one end in a higher proportion than at the other end. Hence there exists no presumption that in the region in which it will be operating the firm would want to make the elasticity of the higher $A P_{k}$ curve different from that of the lower one, i.e. that it would want to decrease the percentage gap between the average and the marginal productivity of capital, thus making the more efficient technology also more "relatively labor-șaving." Alternatively expressed, 
Figure 3 provides a further explanation of our negative proposition. $O R$ is the aggregate revenue function of the firm, $O C_{1}$ its pre-innovation long run aggregate cost function, $O C_{2}$ its post-innovation long run aggregate cost function. $O m_{1}$ is the pre-innovation profit maximizing output, $\mathrm{Om}_{2}$ the post-innovation profit maximizing output. If the

\section{FIGURE 3}

Graphic Illustration of the Negative Proposition

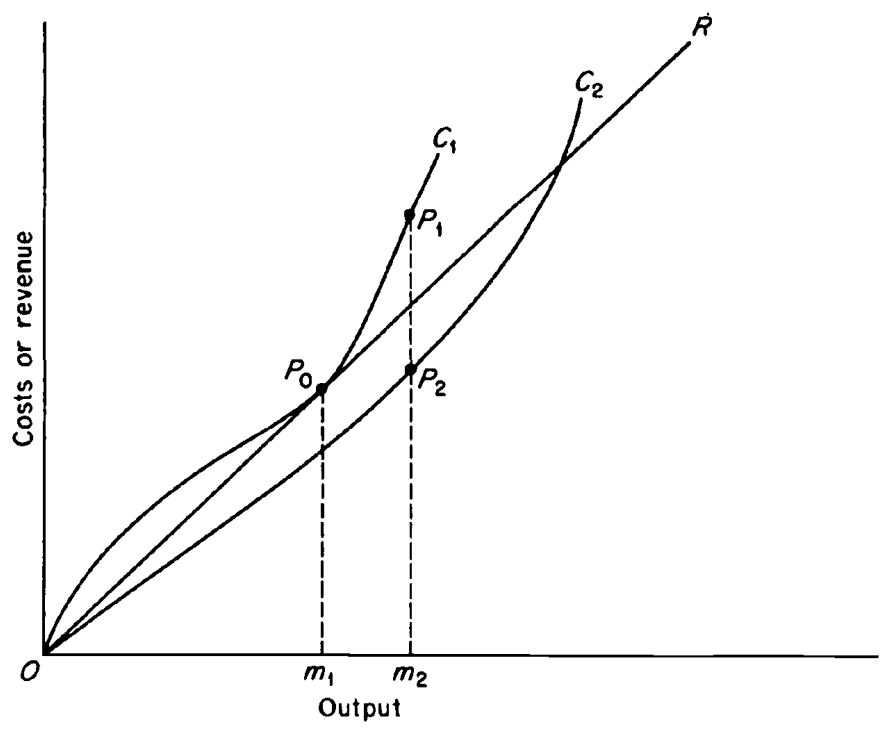

inventions are capable of yielding a 10 per cent increase in the total product for all conceivable factor mixes with which a given output can be produced, then the optimum factor mix will be the same in $P_{2}$ as it is in $P_{1}$, except for the random qualification expressed in footnote 3. Before the inventions all other factor mixes lay on higher cost functions than $O C_{1}$, hence the other factor mixes stay handicapped too under the improved circumstances. The argument applies also to monopolistic selling as long as the ruling factor prices are given to the

when the firm is in $K_{1}$ an effort is likely to be made to find for the next period a higher $A P_{k}$ curve which is particularly high in $K_{2}$; this changes the arc-elasticity of the $A P_{k}$ curve for the jump from $K_{1}$ to $K_{2}$ in one direction, but changes the arc-elasticity of the curve for the jump from $K_{2}$ to $K_{3}$ in the other direction, and there exists no presumption that the resulting higher technology is either more "relatively labor saving" or more "relatively capital saving." 
individual firm while it is putting the innovation into effect. In the event of monopolistic selling the $O R$ line acquires a curvature.

The reader will remember that on the micro-economic level on which we are analyzing the problem in Figure 3 (and Figure 4), the test of the character of innovations is whether given all market prices the individual firm is led to use more labor input per unit of capital (or vice versa). But on a macro-economic level the test is whether the factor-price ratios are changed in one direction or the other, for given total macro-economic resource inputs. It is obvious that this is the macro-economic equivalent of the foregoing micro-economic way of looking at the matter.

Figure 4 provides an alternative illustration of the same negative

FIGURE 4

Alternative Illustration of the Negative Proposition and of a Qualification

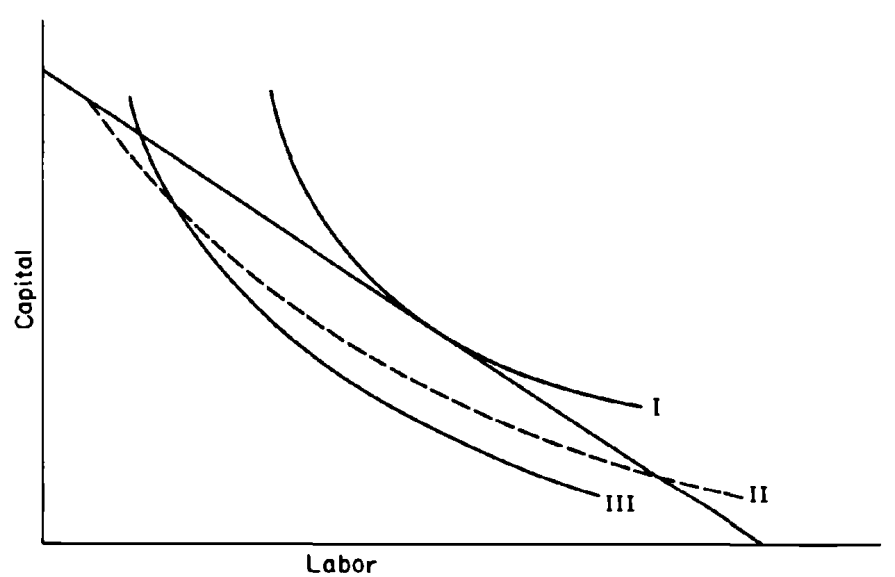

proposition. In this illustration all three isoquants relate to the identical quantity of output. Isoquant I expresses the old technology, while isoquants II and III express newly invented technologies. The ruling factor-price ratio is expressed by the slope of the iso-cost line connecting the axes. The conclusion here is that for the given outputlevel technology III is optimal, although technology II is more relatively labor saving. However, a rise in the relative price of labor will make technology II optimal at a later date, provided that no new invention is made between now and then. This is because a steeper factorprice ratio line would reach tangency with isoquant II below the point 
at which it would reach tangency with isoquant III. We have here our first reason for qualifying our negative proposition, and we are on our way toward positive statements concerning a directing mechanism. It was just shown that the more labor saving isoquant-i.e., isoquant II-becomes superior for a steeper iso-cost line (or factor-price ratio line), and this qualifies our negative proposition for a reason that can be expressed as follows.

The significance of the negative proposition formulated above is at least somewhat reduced-and for some periods it may even be wiped out-by the fact that when the relative scarcity of, say, labor is increasing and factor prices shift correspondingly, certain new methods which were discovered earlier can automatically become economical even though previously they were uneconomical; and the new methods which may qualify with a lag under this heading are necessarily relatively labor saving. Through this mechanism growing relative labor scarcity may conceivably result in a labor saving bias, even if all factors are available to the individual firm in infinitely elastic supply.

Let us now go one step further. If the services of labor or of capital are not in infinitely elastic supply to the individual firm, then it is not enough to qualify our negative proposition concerning the existence of a directing mechanism. In this case, the negative proposition loses its validity completely.

Assume, for example, that the terms on which capital is available to the firm become increasingly unfavorable as the borrowings of the firm increase, while more labor of given quality is available on unchanging terms. In these circumstances the firm does have incentives to seek for the inputs of each period new technological knowledge of a relatively capital-saving kind. In other words, the firm does have incentives to seek improved methods which raise the marginal productivity of labor more than that of capital and thus raise the firm's demand for labor more than its demand for capital. The firm will have incentives to seek such relatively capital-saving innovations because a rise in the price of capital is an effect which the individual firm must take into account in its calculation. It is not merely a macro-economic phenomenon which happens if a great many firms increase their demand for capital, but a phenomenon taking place even if the individual firm alone acts to increase its input of capital. In contrast to this, the macro-economic wage-raising effect of relatively capital-saving innovations is a phenomenon which the individual firm has no reason to take into account in its calculations and hence does not "hold 
against" this type of innovation. The contrary incentives develop if labor is hired in monopsonistic circumstances while the supply of capital is infinitely elastic to the firm. Graphs of the type drawn in Figure 4 will show this up, provided the iso-cost lines are drawn with the appropriate monopsonistic curvature.

Further, it is important to realize that if the firm size becomes determinate not because of the U-shape of the cost curve but because of the rationing of one of the factors of production to the firm, this implies an infinitely inelastic supply of that factor at the pre-innovation input. Hence the incentive to raise the marginal productivity function of this factor is smaller than the incentive to raise the marginal productivity function of the other factor. In this case, too, our quasimonopsonistic results become established.

\section{A POSitive proposition}

Our positive proposition then is that a directing mechanism does come into play as soon as factor scarcities are transmitted to the individual firm by monopsony, or in some quasi-monopsonistic fashion (as in the event of factor rationing which implies infinitely inelastic supply to the firm). From this we may infer that a directing mechanism is quite likely to come into play if the character of the innovations "overshoots" strongly enough in one direction or the other. For, if the innovating activity of a period is slanted strongly enough in a relatively labor-saving direction then the demand for capital is quite likely to rise fast enough to result in excess demand and thus, for the individual firms, in difficulties of financing. For a sustained period the market price of capital lags behind the price at which all the demand would be satisfied. This expresses itself in the fact that the terms of borrowing are made more onerous to the individual firm if it wishes to acquire appreciably more capital than it already has. A monopsonistic situation develops and innovating activity is guided in a more capitalsaving direction (which then puts an end to the monopsonistic situation). The effect of the innovations on the marginal productivity of labor becomes more favorable.

On the other hand, if the innovations of a period overshoot far enough in a relatively capital-saving direction, i.e. if it is primarily the demand for labor which is increased, then the labor market is likely to show signs of excess demand. For a sustained period the market price of labor of various sorts lags behind the price at which all the demand would be satisfied. In a sufficiently tight labor market-which is con- 
sistent with a small degree of over-all unemployment - most individual firms are aware of the fact that increasing the work force in their own establishments requires hiring workers away from other employers on terms more onerous than those implied in the concept of going wage rates for given qualities of workers. This, too, creates temporarily quasi-monopsonistic conditions but in the labor market rather than in the capital market. Hence an incentive is created for seeking more relatively labor-saving improvements. Under the influence of these the marginal productivity of capital fares better, although it is conceivable that within certain limits the effect on the rate of return on capital is offset by a higher propensity to save and a higher rate of investment.

To put it briefly, monopsonistic awareness of factor scarcities is less rare than is commonly believed. Temporary monopsony does not even require "large" firms in any reasonable sense of this word. Such a condition merely requires firms that are large in relation to the markets in which they hire, and acute scarcities may narrow these markets very greatly. A rapidly rising macro-economic demand for a factor is likely to create for a while monopsonistic awareness of relative scarcities. Therefore a sufficient slanting ("overshooting") of innovating activity one way or another may very well lead to this same result. If this is so, incentives are created for seeking innovations whose character is more in accordance with the existing macro-economic resources position.

A word should be added here about the role of monetary fiscal policy. We said a moment ago that innovations which overshoot in a capital-saving direction create a monopsonistically observable labor scarcity, and that, therefore, such overshooting tends to be selfcorrecting. It is necessary, however, to add that if this kind of overshooting lasts long enough, the labor scarcity disappears and the directing mechanism breaks down. The reason is that a sufficiently pronounced and sufficiently protracted weakness of the trend in rates of return on investment (coupled with rigidities in the money-wage and price level) leads to the Keynesian variety of unemployment. This type of unemployment expresses the paradox that a relative labor scarcity (insufficient marginal productivity of capital) may indirectly result in an excess supply of labor. Once the paradox has developed the directing mechanism is put out of commission. The mechanism can be called to life again by policies which raise the level of effective demand, i.e., eliminate the paradoxical excess supply of labor, and it 
is advisable to use such policies with moderation even at an early stage to prevent the Keynesian paradox from developing.

Earlier we also said that overshooting in a labor-saving direction tends to create a monopsonistically observable scarcity of capital which should guide innovating activity into more capital-saving channels. In such circumstances government policy can play a harmful role by making too ambitious efforts to eliminate the relative excess of labor, i.e. by creating a monopsonistically observable scarcity of labor as well as of capital. This last sentence involves, of course, a value judgment because, while a government policy of the sort which is here criticized would indeed weaken the directing mechanism, such a policy could be said to accomplish socially desirable results directly, without the guiding mechanism of the market. Nevertheless, the statement will probably be acceptable to those who wish to aim at reliance on market forces, coupled with corrective policies, rather than at a condition of overfull utilization of all resources coupled with rather comprehensive controls.

\section{MACRO-ECONOMIC ELABORATION}

The macro-economic elaboration on our theme will take its departure from a more flexible variant of the Harrod-Domar type of approach. This version which was used also in earlier writings of the present writer will here be formalized somewhat further.

The Harrod-Domar type of approach places in the foreground a macro-economic relationship expressed by the equation

$$
\frac{d Y}{d t} \cdot \frac{d K}{d Y}=s Y
$$

where $Y$ is output or income, $t$ is time, $K$ is the capital stock, and $s$ is the average propensity to save (so that $s=S / Y$, where $S$ is the aggregate saving of a period).

This relationship is intended to be a condition of dynamic equilibrium (smooth or sustained growth), rather than merely an identity. To make the equation a condition of smooth growth, it is necessary to add

$$
\begin{aligned}
& Y=F(L, K) \\
& S=f(Y)
\end{aligned}
$$


A more complete formulation would include further independent variables in the production function 2 , and also in the saving function 3.

We now turn to an essential point which conventionally receives too little attention. The conventional, very rigid version of the HarrodDomar approach implies the following constraint:

$$
\frac{d Y}{d K}=\frac{Y}{K}=\text { constant }
$$

The only reasonable interpretation of this constraint is that smooth growth cannot continue in the event of a rising capital-output ratio, i.e. of a falling $Y / K$, and that the case of a rising $Y / K$ ratio may be disregarded (perhaps because the equations are intended to formulate the minimum conditions of smooth growth). In other words, the only reasonable interpretation of (4) is to postulate, or to require for smooth growth, nondiminishing returns to capital, in the sense of a nondiminishing $Y / K$ ratio. This point is rarely made clear in discussions based on equation (1) or on equivalents thereof.

What I consider to be a necessary (and for the present purpose, adequate) relaxation of this approach-a more flexible version which I have used in my earlier analysis of growth problems-has the following main characteristic. The constraint expressed in (4) is replaced by the constraint:

$$
\frac{Y}{K} \cdot \frac{P}{Y}=\pi \geqslant \pi_{0}
$$

where $P$ is the income going to the owners of capital (profit plus interest), $\pi$ is the rate of return on capital, and $\pi_{0}$ is the minimum below which $\pi$ cannot decline because of risk-premium requirements.

What $I$ am suggesting here is that the constraint must be made to relate not to the capital-output ratio, or to the $Y / K$ ratio, but to the algebraic product $Y / K \cdot P / Y$ which is the rate of return on capital. Furthermore, the constraint should not postulate that in the economy with which we are concerned, e.g., the American economy, $Y / K \cdot P / Y$, is at a floor level below which it cannot be reduced; the constraint should merely postulate that there exists a minimum requirement for $Y / K \cdot P / Y$, at some level.

The concepts developed earlier can now be applied to this macroeconomic framework. We shall assume that in the kind of economy 
which we are studying the capital stock is rising at a greater proportionate rate than the labor force, and that along given production functions this would reduce $Y / K .{ }^{4}$ Whether along given production functions $P / Y$ would rise, or fall, or stay unchanged depends on the elasticity of substitution and is therefore not entirely certain. ${ }^{5}$ But $Y / K \cdot P / Y$ would be declining. As for the effect of innovations, a sufficient quantity of innovating activity would always prevent the $Y / K$ ratio from declining; and a sufficiently pronounced relatively labor-saving effect of the innovations would always prevent the $P / Y$ ratio from declining.

This last sentence concerning the effects of innovations has been formulated in such a way as to take account of the fact that the observable trends in $Y / K$, in $P / Y$, and in the algebraic product of these (i.e. in $\pi$ ), depend not merely on innovations but on the joint effect of innovations, movements along production functions, and changes in the product mix.

As for the observable trends in these various ratios, the available data for the United States show that in the long run the aggregative $Y / K$ ratio has not declined. Nor does this ratio show a falling trend in some other countries for which we have data. This points to a sufficient quantity of innovating activity to maintain, or even slightly to raise in the long run, the average productivity of the factor of production whose supply has been rising the most rapidly. Consequently, the average productivity of the factors whose supply has been rising in lesser proportion than that of capital shows a pronounced uptrend, and innovating activity may be regarded as quantitatively sufficient by reasonable standards.

The factor-saving effects have been distributed so that an appreciable and consistent uptrend in real wage rates results, and at the same time, that distribution probably results in a mild long-run lowering of the rates of return on investment (although this lowering, or "downtrend," does not show for all subperiods of reasonable duration which can be distinguished in long-run materials). When allowance is made for the labor income and profit income of the self-employed, the

\footnotetext{
${ }^{4}$ This assumes that on a given level of knowledge the economies of scale would have been exploited long ago.

${ }^{5}$ It seems to me very likely that $P / Y$ would decline. For example, if the American capital stock were doubled with absolutely no technological progress and no growth of employment, the rate of return on capital would hardly be higher than one-half of its present value, and wages would no doubt rise.
} 
relative share of labor has not changed much in the long run; it probably has increased to some extent.

It is possible to conclude that in the long run the distribution of the factor-saving effects has come out "just about right," in that rates of return on investment have not declined to a level which would have been too low for sustained investment activity. For the rest, the effect of innovations, along with that of capital formation, has been to raise real wages. In a sense, the innovations have been neither too capitalsaving nor too labor-saving. But we must guard against accepting the (in this sense) correct results of innovating activity as a cogent proof of the existence of the previously discussed directing mechanism.

That directing mechanism should come into operation whenever the relative labor-saving effect of innovations overshoots to the point where there develops "monopsonistic" awareness of a capital shortage; and whenever the relative capital-saving effect of innovations overshoots to a point where there develops monopsonistic awareness of a labor shortage. While a directing mechanism of this sort is very likely to set limits to the overshooting in either direction, I am not familiar with observations which would establish the conclusion that a somewhat more pronounced capital-saving effect than that actually developed would have monopsonistically transmitted a chronic labor shortage to the individual firm. Neither am I familiar with observations which would establish the conclusion that a somewhat more pronounced labor-saving effect than that which has developed would have monopsonistically transmitted a chronic capital shortage to the individual firm. To me it seems tempting to suggest that the kind of directing mechanism outlined above has played a role in keeping the relative factor-saving effects of innovations within bounds. Much stronger claims could not be justified at present.

The alternative proposition which qualifies the negative proposition illustrated by Figure 4 may conceivably point to a nonmonopsonistic directing mechanism. One way of expressing this alternative proposition is to say that if, for the time being, a more capital-saving innovation is neither better nor worse than a more labor-saving one, then, in the absence of further inventions, the more labor-saving innovation will later become superior.

Whenever the monopsonistic mechanism previously discussed or this latter alternative adjustment process is at work, the characteristics of technological change contribute to the avoidance of underutilization. One disadvantage of basing economic development in primitive 
countries on Western knowledge is that Western technological progress seems to have adjusted to Western resource positions which, of course, are different from the resource positions of primitive countries. Thus, the present problem of primitive countries frequently is to choose between a backward capital-saving technology and an innovated Western labor-saving technology. A genuine adjustment process in primitive countries would, on the other hand, make innovated capital-saving technologies available to them.

\section{COMMENT}

Edwin MANSFIELD, Carnegie Institute of Technology

In his present paper, William Fellner returns to a subject considered in his book on economic growth. ${ }^{1} \mathrm{He}$ asks the following question: What mechanisms exist in a capitalist economy to direct inventive activity into the correct channels? If capital-or labor-becomes relatively "abundant," are there market forces stimulating the search for labor-saving —or capital-saving-inventions?

First, he considers a perfectly competitive economy and concludes that no such forces exist. Next, he allows imperfections to be present in the factor markets and points out that if these imperfections reflect macro-economic scarcities, firms will have the incentive to seek out inventions of the proper type. Then he goes on to suggest that this sort of mechanism may have prevented innovations from becoming too "capital saving" or too "labor saving."

Fellner's two central propositions seem formally correct. In a perfectly competitive economy I can see no reason why a firm, in searching for new methods, should prefer ones that are relatively capital saving or relatively labor saving. What matters is the extent to which profits will increase. Moreover, if there are imperfections in the factor markets of the sort he assumes, it seems clear that firms will find innovations of the proper type more profitable to install.

However, I think he seriously understates the significance of a qualification he mentions. Although firms may have no preference for inventions of the proper type, a "sufficient" quantity of such inventions may be available as a by-product of past research efforts. In the course of project research and other inventive activities, many bits of

${ }^{1}$ Trends and Cycles in Economic Activity, New York, Holt, 1956, pp. 220-222. 
technical knowledge are unearthed that can only be applied economically under subsequent factor prices. Presumably, the extent of past inventive efforts determines (at least in part) whether the supply of such innovations is "sufficient."

Turning from Fellner's paper, I would like to describe briefly some related work of my own. Part of a larger project on technical change that I have been conducting, ${ }^{2}$ this work deals with the factors influencing a firm's spending on research and development. At this point, only the first parts of this study have been completed. But the results to date and the broad lines of the investigation may be worth presenting.

I shall begin by presenting a very simple model to help explain the short-term variation in a firm's expenditures on research and development. Then I shall describe the results of some preliminary tests to which it has been subjected. Finally, I shall outline how this simple model fits into the overall study of $\mathrm{R}$ and $\mathrm{D}$ expenditures. Note at the outset that the analysis applies only to industries whose $R$ and $D$ is mainly privately financed (chemicals, petroleum, etc.) and that the results so far are extremely tentative.

In its simplest form, the model assumes three things. First, it assumes that a firm's managers, when they determine how much to spend on $\mathrm{R}$ and $\mathrm{D}$ during the coming year, begin by taking this year's expenditure as a base from which to figure. Second, it assumes that they have some target percentage of sales in mind and that they apply this percentage to their sales forecast for the coming year to obtain a target figure for $\mathrm{R}$ and $\mathrm{D}$ expenditures. For the $i^{t h}$ firm, let this percentage be $\alpha_{i 1}$. Third, it assumes that they set the R and D budget so as to move a certain fraction of the way toward this target. For the $i^{\text {th }}$ firm, let this fraction be $\alpha_{i 2}$. Thus, if $r_{i}(t)$ is the $i^{\text {th }}$ firm's $\mathrm{R}$ and $\mathrm{D}$ budget for year $t, R_{i}(t-1)$ is its actual expenditure in year $t-1$, and $s_{i}(t)$ is its sales forecast for year $t$,

$$
r_{i}(t)=R_{i}(t-1)+\alpha_{i 2}\left[\alpha_{i 1} s_{i}(t)-R_{i}(t-1)\right] .
$$

These assumptions seem to accord at least roughly with the results of various surveys. For example, the National Science Foundation, having interviewed officials of about 200 corporations, concludes that firms generally take existing expenditures as a base in formulating $\mathbf{R}$

\footnotetext{
${ }^{2}$ This work has been financed principally by a contract with the Office of Special Studies of the National Science Foundation.
} 
and $\mathrm{D}$ budgets. ${ }^{3}$ It also finds that the most prevalent way in which firms determine the "optimal" level of $\mathrm{R}$ and $\mathrm{D}$ expenditures is by taking some percentage of sales. ${ }^{4}$ And it points out the value placed by firms on the stability of their research organizations. ${ }^{5}$ Because of the long-term nature of research projects and because changes in sales may only be temporary, one would expect $\alpha_{i 2}$ to be considerably less than unity.

If we go on to assume that the forecast sales equal the actual sales and that the actual $R$ and $D$ expenditures equal the budgeted amount in equation 1 plus a random error term, ${ }^{6}$ we have

$$
R_{i}(t)=R_{i}(t-1)+\alpha_{i 2}\left[\alpha_{i 1} S_{i}(t)-R_{i}(t-1)\right]+z_{i}(t),
$$

where $S_{i}(t)$ is the firm's actual sales in year $t$ and $z_{i}(t)$ is a random variable with zero expected value. Letting $\beta_{i 1}=1-\alpha_{i 2}$ and $\beta_{i 2}=\alpha_{i 1} \alpha_{i 2}$, we have

$$
R_{i}(t)=\beta_{i 1} R_{i}(t-1)+\beta_{i 2} S_{i}(t)+z_{i}(t),
$$

and according to the model,

$$
O \leq \beta_{i 1} \leq 1 ; O \leq \beta_{i 2} \leq 1 .
$$

Turning now to the matter of empirical testing, how well does equation 3 fit the past behavior of various firms? Using pre- 1957 data for ten major chemical companies, ${ }^{7}$ I obtained least-squares estimates of $\beta_{i 1}$ and $\beta_{i 2}$. The results-presented in Table 1 -indicate that equation 3 represents these data extremely well. The correlation coefficients are generally 0.99 or higher. The estimates of $\beta_{i 1}$ and $\beta_{i 2}$ generally have the correct signs, they are generally of the expected

S See Science and Engineering in American Industry, Final Report on a 1953-1954 Survey, National Science Foundation, 56-16, Washington, 1956, p. 46. My colleague, Norton Seeber, is currently involved in a similar but more intensive sort of interview study.

4 Ibid., p. 41.

5 Ibid., p. 46.

6 The assumption that sales forecasts are perfect is clearly only a convenient first approximation. Its effect is probably to bias the estimate of $\beta_{i 2}$ toward zero.

${ }^{7}$ The data come from Charles Langenhagen, "An Evaluation of Research and Development in the Chemical Industry," (unpublished M.S. thesis, Massachusetts Institute of Technology, 1958). Included were all firms for which he presented exact figures for twelve or more years, and for which corresponding sales figures could be obtained. He obtained the figures through correspondence with the firms and through annual reports and similar documents. Only the exact figures (not his estimates) are included. Of course, there may be interfirm differences in the definition of research and development. 
TABLE 1

Estimates of $\beta_{i 1}$ and $\beta_{i 2}$, Ten Major Chemical Companies

\begin{tabular}{|c|c|c|c|c|c|c|c|}
\hline \multirow[b]{2}{*}{ Company } & \multirow{2}{*}{$\begin{array}{c}\text { Number of } \\
\text { years }\end{array}$} & \multicolumn{3}{|c|}{ Estimates $^{b}$} & \multicolumn{2}{|c|}{ Standard Errors } & \multirow{2}{*}{$\begin{array}{l}\text { Coefficient of } \\
\text { Determination }\end{array}$} \\
\hline & & $\beta_{i 0}$ & $\beta_{i 1}$ & $\beta_{i 2}$ & $\beta_{i 1}$ & $\beta_{i 2}$ & \\
\hline Allied Chemical & 11 & -.55 & .74 & .0093 & .15 & .0053 & .98 \\
\hline American Cyanamid & 20 & -.41 & .70 & .0177 & .12 & .0059 & .98 \\
\hline Atlas Powder & 20 & -.14 & 1.02 & .0053 & .15 & .0039 & .94 \\
\hline Diamond Alkali & 15 & -.36 & .81 & .0141 & .12 & .0039 & .98 \\
\hline General Analine & 11 & 1.66 & .75 & -.0027 & .28 & .0146 & .75 \\
\hline Hercules Powder & 25 & -.27 & .88 & .0095 & .11 & .0040 & .97 \\
\hline Hooker Electrochemical & 19 & -.02 & .48 & .0139 & .13 & .0019 & .99 \\
\hline Minnesota Mining & 19 & -.23 & .77 & .0131 & .22 & .0069 & .99 \\
\hline Monsanto Chemical & 24 & -.35 & .65 & .0158 & .14 & .0036 & .99 \\
\hline Union Carbide & 12 & -.92 & 1.10 & .0029 & .11 & .0045 & .99 \\
\hline
\end{tabular}

SOURCE: Charles Langenhagen, "An Evaluation of Research and Development in the Chemical Industry," Unpublished M.S. thesis, Massachusetts Institute of Technology, 1958, and Moody's Industrials.

${ }^{a}$ The number of years for which data could be obtained for $R_{i}(t), R_{i}(t-1)$, and $S(t)$. The years are consecutive and end with 1956 in all cases but Diamond Alkali and Union Carbide where the last year is 1955.

${ }^{b}$ In computing the regression, all variables were measured in units of millions of dollars. $\beta_{i 0}$ is the intercept of the regression-which according to the model should be zero. Although no formal tests were carried out, it seems unlikely that many of these estimates would be statistically significant. However, it is noteworthy that in almost every case the estimate is negative.

${ }^{c}$ The square of the coefficient of correlation.

order of magnitude, and despite relatively few degrees of freedom, they are generally statistically significant. ${ }^{8}$

How well does equation 3 forecast the expenditures on $\mathrm{R}$ and $\mathrm{D}$ of these firms? Taking each firm's sales in 1957 as given and using the estimates of $\beta_{i 1}$ and $\beta_{i 2}$ in Table 1 , I used equation 3 to forecast each firm's 1957 R and D expenditures. (I did not have data on their R and $\mathrm{D}$ expenditures in later years.) The results-shown in Table 2indicate that the forecasting errors for individual firms are generally from 5 to 10 per cent and that for the group as a whole the error is only about 2 per cent. This is considerably better than the performance of three standard naive models. ${ }^{9}$

${ }^{8}$ In three cases, the estimates violate the inequalities in equation (4) but in every case the standard errors are so large that this could well be due merely to sampling fluctuations.

${ }^{9}$ The three naive forecasts are (1) that expenditures next year will equal those this year [i.e. that $R_{i}(t)=R_{i}(t-1)$ ], (2) that expenditures next year will differ from those this year by the same amount that expenditures this year differed from those last year [i.e. that $\left.R_{i}(t)=2 R_{i}(t-1)-R_{i}(t-2)\right]$, and (3) that expenditures next year will differ by the same per cent from those this year as this year's expenditures differed from those last 
TABLE 2

Comparison of Actual and Forecast R AND D EXPenditures

Ten Major Chemical Companies (millions of dollars)

\begin{tabular}{lrr}
\hline \multicolumn{1}{c}{ Company } & Actual & Forecast \\
Allied Chemical & 17.5 & 18.7 \\
American Cyanamid & 22.7 & 24.7 \\
Atlas Powder & 2.8 & 2.4 \\
Diamond Alkali & 3.9 & 4.2 \\
General Analine & 5.8 & 5.1 \\
Hercules Powder & 10.2 & 11.3 \\
Hooker Electrochemical & 2.8 & 2.6 \\
Minnesota Mining & 16.4 & 14.1 \\
Monsanto Chemical & 22.7 & 21.1 \\
Union Carbide & 55.0 & 52.4 \\
\multicolumn{1}{c}{ Total } & 159.8 & 156.6 \\
\hline
\end{tabular}

SOURCE: see Table 1. For each firm, the actual and forecast expenditures refer to the last year for which Langenhagen gives exact figures. For Diamond Alkali and Union Carbide, this is 1956. For the others it is 1957.

Thus, on the basis of the little evidence available so far, this modelhighly simplified though it is-seems to fit past data quite well and to be a promising device for short term forecasting (at least in the chemical industry). ${ }^{10}$ However, this result is still only a first step toward an understanding of the basic mechanisms governing the level of $\mathrm{R}$ and $\mathrm{D}$ expenditures. Hopefully, it will be a useful first step.

This result suggests that to structure the problem and simplify it somewhat, it may be a fruitful strategy to regard $\alpha_{i 1}$ and $\alpha_{i 2}$ as the key variables to be explained in a broader model. The problem then is to investigate the factors that influence these two parameters. In the months ahead I shall try to do just that.

By taking each of several industries and making interfirm comparisons at various points in time, I shall try to measure the effects of various factors on $\alpha_{i 1}$ and $\alpha_{i 2}$. For example, $\alpha_{i 2}$ may depend on a firm's profitability and size. Naturally, the extent to which data are available

year [i.e. that $R_{i}(t)=R_{i}(t-1)^{2} / R_{i}(t-2)$ ]. The root-mean-square error for the forecasts in Table 2 is 1.48 . It is 3.61 for the first type of naive forecast, 2.24 for the second type, and 2.2 for the third type.

${ }^{10}$ Of course, one would need a forecast of next year's sales for the firm or the industry. But such forecasts are now collected in various surveys. Moreover, it may be that $S_{i}(t-1)$ provides almost as good an approximation to the forecast as $S_{i}(t)$. There are also the usual problems of aggregation if one is interested in using a single equation to forecast for the entire industry. But these problems may not be so very troublesome here. 
will determine how thoroughly some of the relevant hypotheses can be tested.

Moreover, I will try to measure the effects of certain variables that might cause differences over time in the parameters for a given firm. Although equation 3 may be useful for short term forecasting, it is unlikely to be of value over longer periods because $\alpha_{i 1}$ and $\alpha_{i 2}$ are likely to change with time. For example, $\alpha_{i 2}$ may depend on factors such as the tightness of the market for research personnel, and $\alpha_{i 1}$ may depend on tax rates and the anticipated profitability of research.

To sum up, this model provides a good representation of the data available thus far. If further work shows it fits data for other firms (and other industries) equally well, it may be quite useful for short term forecasting. Moreover, it may also be a worthwhile first step toward the construction of a more fundamental model explaining the level of $\mathbf{R}$ and $\mathbf{D}$ expenditures in a firm or industry. The investigation that will soon be under way of inter-firm and temporal differences in the parameters should bring us closer to this goal.

\section{COMMENT}

\section{Charles J. Hitch, The RAND Corporation}

The papers and the discussants have expressed many views on the productivity of research and development. As we all know, Griliches has measured it in one instance and come up with a formidable number (but he does not include the cost of unsuccessful research in his denominator). Minasian succeeds in "explaining" interfirm differences in profits in one industry by differential research activity; others have made similar attempts in other industries with negative results. Arrow has given us reasons for believing that the social productivity of development (and especially of research) is higher than the appropriable private productivity, but he makes no attempt to estimate either quantity. At one extreme, several discussants have referred to industrial research and development as a "fashion" whose main purpose is to impress the stock buying public, and wondered out loud whether, in the aggregate, it is worth the cost. Machlup, in particular, wonders whether more of it is worth the marginal cost, which is a great deal higher than the average cost.

I can present no numbers to reconcile these divergent views but there is, I think, some relevant empirical evidence from an industry 
that has spent and is spending very heavily on research and development; namely, the military industry. By whatever arbitrary index of military power one measures the productivity of this industry, it has increased since World War II not by a few percentage points per annum but by many orders of magnitude. And it has increased not because of a larger allocation of resources or their more efficient use within given technological state-of-the-art constraint, but because of technological progress stemming from a very large, deliberate, and expensive research and development program. By far the most important factor has been the successful development and later improvement of, first, fission and then fusion bombs. But many other developments have also contributed in a major way; for example, those in delivery vehicles, guidance techniques, and radar. To mention just one example which does not depend on nuclear energy, we have developed antiaircraft missiles which could annihilate a World War II style bomber raid.

This tremendous increase in our military power, measured in an absolute sense, has been obscured by the fact that the Russians, with a similar reliance on research and development, have increased their power to perhaps a greater extent, so that during part of this period our relative power has been declining. We are pessimistic about air defenses in spite of our great progress because qualitative improvements in air offense have proceeded even more rapidly.

Nevertheless, if we had not spent lavishly on military research and development, if we had used the same funds to acquire additional World War II type forces, our relative power would have declined much more precipitously. In fact, we should scarcely be participating in the race.

I have tried to think of some reason why the military industry should be unique in this respect but I cannot. Throughout most of history military technology has advanced very slowly, as in most other industries, sparked by more or less chance inventions at widely separated intervals. What has been new since 1940 has been the deliberate. seeking of inventions within the framework of billion dollar research and development programs. Perhaps somewhat similar measures would produce similar results in some other industries. Perhaps the divergence between social productivity and private productivity in research and development is a matter of great and general practical significance. 